\title{
The Implications of Carbon Taxation on Microgrid Adoption of Small-Scale On-Site Power Generation Using a Multi-Criteria Approach ${ }^{1}$
}

\author{
Afzal S. Siddiqui, Anibal T. de Almeida ${ }^{2}$, Chris Marnay, and F. Javier Rubio ${ }^{3}$
}

Environmental Energy Technologies Division

Lawrence Berkeley National Laboratory

1 Cyclotron Road, MS 90-4000

Berkeley CA 94720

http://eetd.lbl.gov/EA/EMP/emppubs.html

December 2001

\footnotetext{
${ }^{1}$ The authors are grateful to Kristina S. Hamachi, Mark Khavkin, Emily S. Bartholomew, Mithra M. Moezzi, and Tim Lipman, as well as Consortium for Electric Reliability Technology Solutions (CERTS) partners Robert H. Lasseter, Abbas A. Akhil, and Jeffrey Dagle for helpful comments and discussion. This work was supported by funding from the U.S. Department of Energy and the California Energy Commission.

${ }^{2}$ Instituto de Sistemas e Robótica, Universidade de Coimbra, Coimbra, Portugal.

${ }^{3}$ Instituto de Investigacion Tecnologica, Universidad Pontificia Comillas, Madrid, Spain.
} 


\section{Table of Contents}

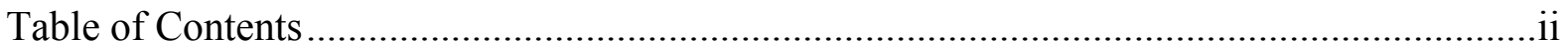

List of Figures and Tables........................................................................................... iii

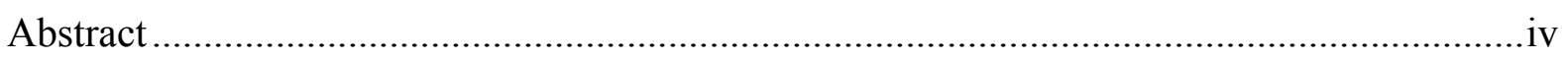

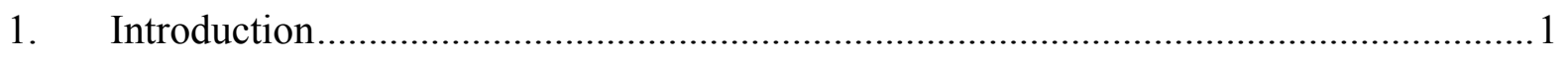

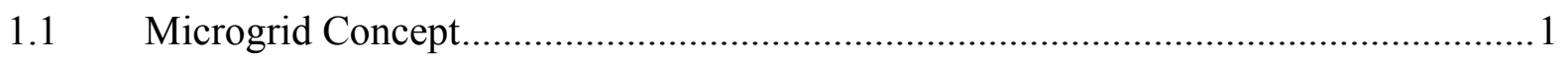

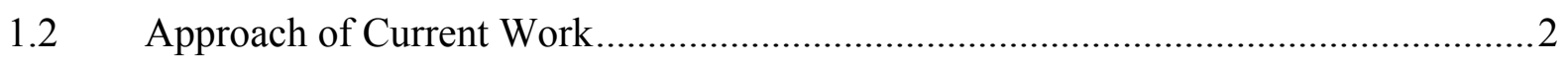

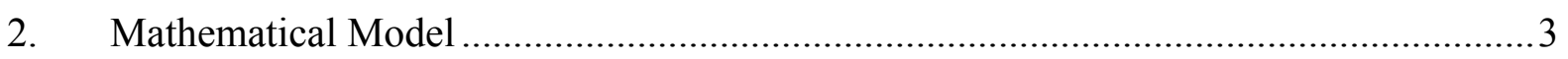

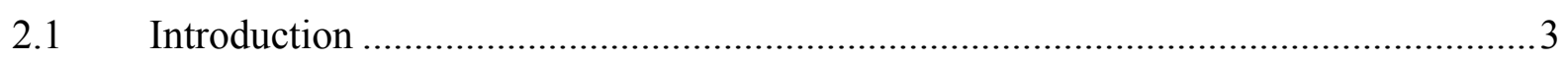

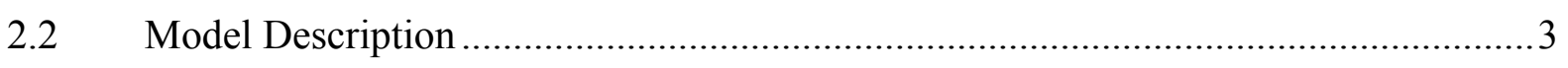

2.3 General Algebraic Modelling System (GAMS) .....................................................

2.4 Mathematical Formulation ............................................................................ 4

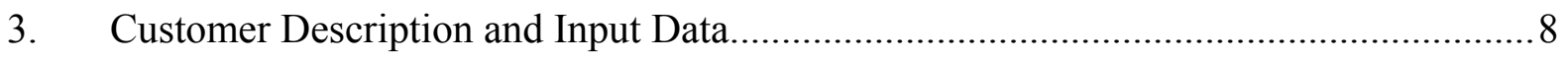

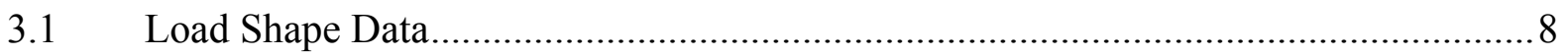

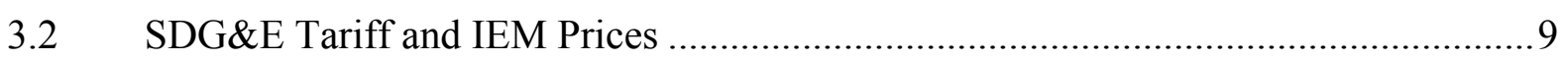

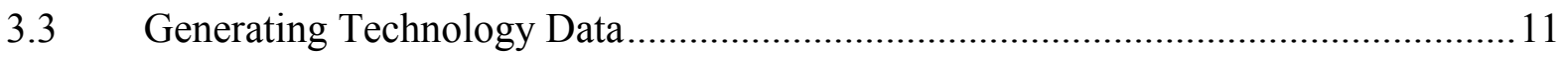

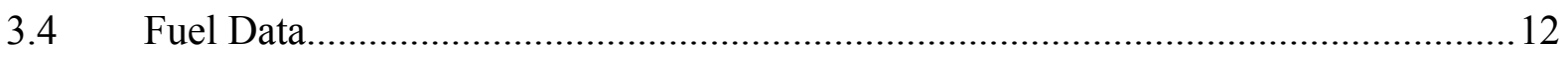

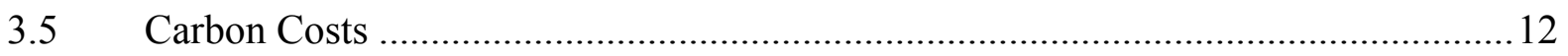

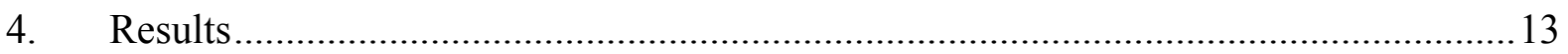

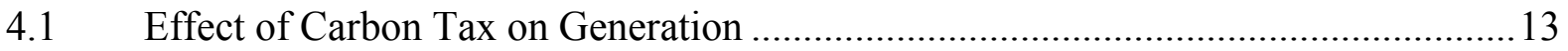

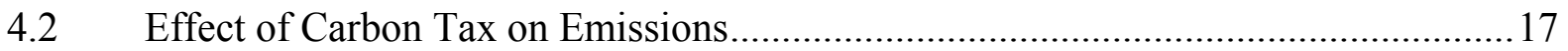

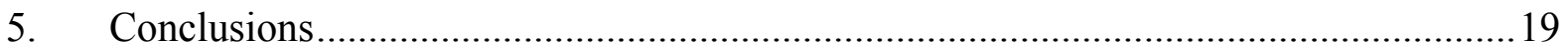

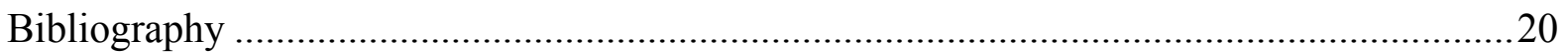




\section{List of Figures and Tables}

Figure 1. Office Monthly Peak Load

Figure 2. California Independent System Operator (CAISO) IEM Price Summary for 2000.. 10 Figure 3. Solar Insolation as a Fraction of Historical Peak Value Received in the Southern

California Test Area....

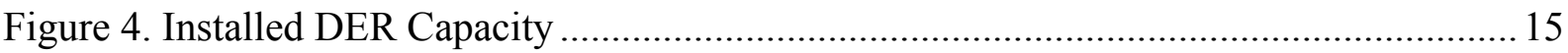

Figure 5. Installed DER Technologies for the Base Case ......................................................... 15

Figure 6. Installed DER Technologies for the Disco SDG\&E Tariff Case …........................... 15

Figure 7. Installed DER Technologies for the 25\% Subsidy Case ....................................... 15

Figure 8. Installed DER Technologies for the 50\% Subsidy Case ......................................... 15

Figure 9. Effect of Carbon Tax on Energy Generation and Costs for the Base Case ............... 16

Figure 10. Effect of Carbon Tax on Energy Generation and Costs for the Disco SDG\&E

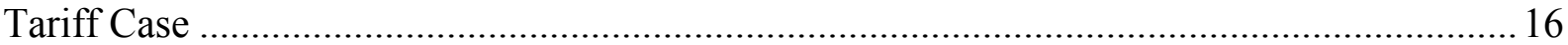

Figure 11. Effect of Carbon Tax on Energy Generation and Costs for the 25\% Subsidy Case 16

Figure 12. Effect of Carbon Tax on Energy Generation and Costs for the 50\% Subsidy Case 16

Figure 13. Percentage Cost Increase Due to Carbon Tax .................................................... 17

Figure 14. Cumulative Percentage Decrease in Carbon Emissions ........................................... 18

Figure 15. Carbon Emissions Comparison for the Base Case …............................................. 19

Figure 16. Carbon Emissions Comparison for the Disco SDG\&E Tariff Case........................ 19

Figure 17. Carbon Emissions Comparison for the 25\% Subsidy Case .................................... 19

Figure 18. Carbon Emissions Comparison for the 50\% Subsidy Case................................... 19

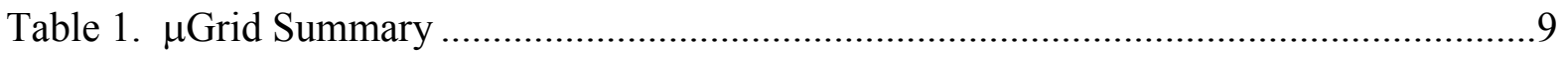

Table 2. SDG\&E AL-TOU (General Service Time-of-Use) Tariff Information....................10

Table 3. SDG\&E AL-TOU Fixed Customer Charges ........................................................

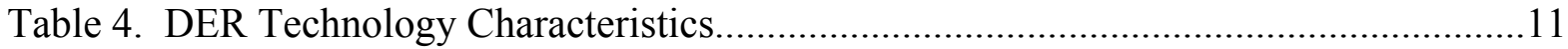

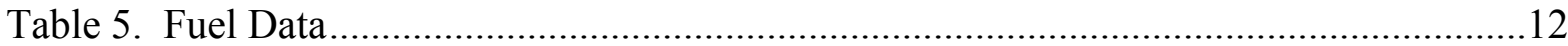

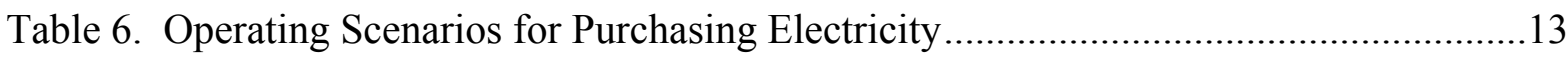

Table 7. Percentage of Carbon Emissions from Macrogrid.................................................16 


\begin{abstract}
The electricity supply system is undergoing major regulatory and technological change with significant implications for the way in which the sector will operate (including its patterns of carbon emissions) and for the policies required to ensure socially and environmentally desirable outcomes. One such change stems from the rapid emergence of viable small-scale (i.e., smaller than $500 \mathrm{~kW}$ ) generators that are potentially competitive with grid-delivered electricity, especially in combined heat and power configurations. Such distributed energy resources (DER) may be grouped together with loads in microgrids ( $\mu \mathrm{Grids}$ ). These clusters could operate semi-autonomously from the established power system, or macrogrid, matching power quality and reliability more closely to local end-use requirements. The impact of a carbon tax on DER adoption by the $\mu$ grid and resulting carbon emissions is assessed here, using a combined cost approach. In general, we find that increases in the carbon tax stimulate DER adoption, with the added DER capacity being overwhelmingly from "green," or environmentally benign technologies. Furthermore, more carbon emissions abatement is possible at lower levels of carbon tax if "green" DER technologies are granted subsidies towards their turnkey costs. However, these results are sensitive to the regulatory environment, however. For example, carbon emissions abatement is greater under the tariff scenario than in one that allows the $\mu$ grid to purchase electricity from the open market.
\end{abstract}




\section{Introduction}

\subsection{Microgrid Concept}

The analysis included in this paper is built on the vision that future electric power systems will not be organized as monolithic centralized systems as they are today. Rather, a significant share of electricity will be generated and consumed locally within microgrids ( $\mu$ Grids) that are designed and controlled to meet local requirements. $\mu$ Grids will operate according to their protocols and standards, will match power quality and reliability to individual load requirements, and will exploit efficiency improving technologies, especially those using combined heat and power (CHP).

The expectation that distributed energy resources (DER) will emerge over the next decade or two to reshape the way in which electricity is supplied stems from the following hypotheses:

1. Small-scale generating technology, including renewable, thermal, and chemical, will improve significantly in terms of cost and performance,

2. Setting constraints, environmental concerns, fossil fuel costs and availability, and other limits will impede continued expansion of the existing electricity supply infrastructure,

3. The potential for application of small-scale CHP technologies will tilt power generation economics in favor of generation based closer to heating and/or cooling loads,

4. Customers' requirements for service quality and reliability levels which cannot be met only by conventional grid connection will intensify, and

5. Power electronics will enable interconnection of asynchronous devices with the existing power system and operation of semi-autonomous systems allowing seamless interaction of DER with the main power system.

Together, these forces will make generation of electricity from resources based close to end uses competitive with central station generation for a significant number of customers.

This research is built upon the fundamental concept of the $\mu \mathrm{Grid}$, which could contribute to a more decentralized power system. A $\mu$ Grid consists of a localized semi-autonomous grouping of loads, generation, and storage operating under a form of co-ordinated local control, either active or passive. The $\mu \mathrm{Grid}$ is connected to the current power system, or macrogrid, in a manner that allows it to appear to the wider grid as a good citizen. That is, the $\mu$ Grid performs as a legitimate entity under grid rules, e.g., as what we currently consider a normal electricity customer or generating unit.

The $\mu$ Grid would most likely exist on a small, dense group of contiguous geographic sites that exchange electrical energy through a low voltage (e.g., $480 \mathrm{~V}$ ) network and heat through exchange of working fluids. In warmer climates, the commercial and industrial sector heat loads may well include absorption cooling. The generators, loads, and storage within the cluster are placed and co-ordinated to minimize the joint cost of serving internal electricity and heat demand, given prevailing market conditions, while operating safely and maintaining power balance and quality. This pattern of power generation and consumption is distinctly different from existing power systems in that the energy sources and sinks within the cluster can be maintained in a balanced and stable state without active external control or support, possibly within a passively controlled plug and play system.

Traditional power system planning and operation hinges on the assumption that the selection, deployment, and financing of generating assets will be tightly coupled to changing 
requirements and that it will rest in the hands of a centralized authority. $\mu$ Grids will develop in accordance with their independent incentives. The ongoing deregulation of central generation represents the first step towards abandoning the centralized paradigm, while the emergence of $\mu$ Grids represents the second. Because $\mu$ Grids will develop their own independent operational standards and expansion plans, the overall growth pattern of the power system will be significantly different. In other words, the power system will be expanding more in accordance with dispersed independent goals. Co-ordinated global planning will, thus, be influenced by the emergence of this new paradigm. ${ }^{4}$

The emergence of the $\mu$ Grid partially stratifies the current strictly hierarchical centralized control of the power system into at least two layers. The upper layer macrogrid is the one with which current power engineers are familiar, i.e., large central station generation interconnected to the high voltage meshed power grid. A centralized control center dispatches a limited set of large assets in keeping with contracts established between electricity and ancillary services buyers and sellers, while maintaining the energy balance and power quality, protecting the system, and ensuring reliability. At the same time, where they operate, a lower layer of $\mu$ Grids jointly controls local generation, load, and storage to meet end use requirements for energy and power quality and reliability (PQR). Exchange of power between the $\mu \mathrm{Grid}$ and the macrogrid can be made whenever there are economic benefits for such an exchange, i.e., in order to minimize the overall cost of meeting the $\mu$ Grid's energy service requirements.

Control of the generating and transmission assets of the macrogrid is governed by extremely precise technical standards that are uniform on regional scales, and the key parameters of the grid, such as frequency and voltage, are maintained strictly within tight tolerances. This control paradigm ensures overall stability and safety and attempts to guarantee that power and ancillary service delivery between sellers and buyers is as efficient and reliable as reasonably possible. However, it should be recognized that uniform standards of PQR are unlikely to match well with the optimal requirements of individual end uses that are highly heterogeneous, e.g., with server farms at one end of the reliability requirement spectrum and irrigation water pumps at the other. $\mu$ Grids move the PQR choice closer to the end uses and permit it to match the end use's needs more effectively. Therefore, $\mu$ Grids can improve the overall efficiency of electricity delivery at the point of end use; and as $\mu$ Grids become more prevalent, the PQR standards of the macrogrid can ultimately be matched to the purpose of bulk power delivery.

\subsection{Approach of Current Work}

The approach taken in this work is strictly customer oriented. This stands in contrast to past study of DER, which has tended to consider DER as an additional option available to utility planners and systems (Weinberg, Iannucci, and Reading 1993). A recent study evaluated the applicability of the $\mu$ Grid in organizing onsite generation for industrial application (Piagi and Lasseter 2001). Further, past work has evaluated the benefits of DER in terms of improved power system performance rather than in terms of enhanced customer control (van Sambeek 2000). The starting point is to minimize the cost of meeting the known electrical load of a $\mu$ Grid. Techniques for optimally solving this problem have been developed over many years for planning and operating utility scale systems. Since the customer-scale problem is, at the level of analysis of this paper, essentially no different from the utility-scale problem,

\footnotetext{
${ }^{4}$ It is estimated that DER may supply $20-30 \%$ of the loads.
} 
established methods can be readily adapted. In future work, some of the specific problems related to $\mu$ Grids will be incorporated, such as the central role of CHP and load control of $\mu$ Grid PQR. However, the approach in this work is purely from a traditional power systems economics perspective. While the patterns of potential customer adoption and generation are interesting in themselves, this model is a means for answering two specific questions:

1. How does the presence of a carbon tax stimulate the $\mu$ Grid to install more environmentally benign technologies?

2. Which regulatory frameworks are more conducive to carbon emissions abatement via imposition of a carbon tax?

\section{Mathematical Model}

\subsection{Introduction}

In this section, the second version of the DER Customer Adoption Model (DER-CAM) with a carbon tax capability is presented. This version of the model has been programmed in GAMS (General Algebraic Modeling System) ${ }^{5}$. This section contains a description of GAMS and a description of the present version of the model's mathematical formulation. The results presented are not intended to represent a definitive analysis of the benefits of DER adoption, but rather as a demonstration of the current DER-CAM. Developing estimates of realistic customer costs is an important area in which improvement is both essential and possible. Taking account of the possible benefits of locally adjusting, as well as exploiting, reliability CHP applications are necessary technical enhancements to DER-CAM.

\subsection{Model Description}

In a previous report, the first spreadsheet version of the Customer Adoption Model was described and implemented (Marnay et al. 2000). A follow-up report used GAMS to solve the Customer Adoption Model (Marnay et al. (2001). The current work extends that model to account for carbon taxes. The model's objective function, which has not essentially changed, is to minimize the cost of supplying electricity to a specific $\mu$ Grid by optimizing the distributed generation of part or the whole electricity requirement. In order to attain this objective, the following questions must be answered:

- Which distributed generation technology (or combination of technologies) should the $\mu$ Grid install?

- What is the appropriate level of installed capacity of these technologies that minimizes the cost of meeting the $\mu$ Grid's electricity requirement?

- How should the installed capacity be operated in order to minimize the total bill for meeting the $\mu$ Grid's electricity load?

It is then possible to determine the technologies and capacity the $\mu$ Grid is likely to install, to predict when the $\mu$ Grid will be self-generating and/or transacting with the grid, and to determine whether it is worthwhile for the $\mu$ Grid to disconnect entirely from the macrogrid.

The essential inputs to DER-CAM are:

- The $\mu$ Grid's electricity load profile.

\footnotetext{
${ }^{5}$ GAMS is a proprietary software product used for high-level modeling of mathematical programming problems. It is owned by the GAMS Development Corporation (http://www.gams.com) and is licensed to Berkeley Lab.
} 
- Either the default tariff (assumed to be from San Diego Gas and Electric Company, or SDG\&E) or the California independent system operator (CAISO) imbalance energy market (IEM) price at all hours of the test year (2000), which are alternative electricity purchase options for the $\mu$ Grid.

- Capital, operating and maintenance (O\&M), and fuel costs of the various available DER technologies, together with the interest rate on customer investment.

- Basic physical characteristics of alternative generating technologies.

- Rate of carbon emissions from both the macrogrid and DER technologies.

- Carbon tax rates.

Outputs to be determined by the optimization are:

- Technology (or combination of technologies) to be installed.

- Capacity of each technology to be installed.

- When and how much of the capacity installed will be running during the test year.

- Total cost of supplying the electricity requirement.

- Whether or not the customer should, from an economic point of view, remain connected to the grid.

- The impact of carbon taxes on the installation and operation of DER technologies, both in terms of overall capacity and the choice of equipment.

The important assumptions are:

- Customer decisions are taken based only on direct economic criteria. In other words, the only benefit that the $\mu$ Grid can achieve is a reduction in its electricity bill.

- The $\mu$ Grid is not allowed to generate more electricity than it consumes. On the other hand, if more electricity is consumed than generated, then the $\mu \mathrm{Grid}$ will buy from the macrogrid either at the default tariff rate or at the IEM price. No other market opportunities, such as sale of ancillary services or bilateral contracts, are considered.

- Manufacturer claims for equipment price and performance are accepted without question, nor is any deterioration in output or efficiency during the lifetime of the equipment considered. Furthermore, installation, permitting and other costs are not considered in the capital cost of equipment and start-up and other operating costs are not included.

- CHP benefits, reliability and power quality benefits, and economies of scale in O\&M costs for multiple units of the same technology are not taken into account. This underestimates the benefit of DER to many potential $\mu$ Grids.

\subsection{General Algebraic Modeling System (GAMS)}

GAMS is a proprietary software package that solves optimization problems. The actual mathematical program is modeled via user-defined algebraic equations. GAMS then compiles them and uses standard solvers to solve the resulting problem. The foremost advantage of using GAMS is that it allows researchers to build models that can be quickly altered to address different situations or perform sensitivity analysis.

\subsection{Mathematical Formulation}

This section describes intuitively the core mathematical problem solved by DER-CAM. It is structured into three main parts. First, the input parameters are listed. Second, the decision 
variables are defined. Third, the optimization problem is described for two possible tariff options.

\subsubsection{Variables and Parameters Definition}

\subsubsection{Parameters (input information)}

\section{Time Scale Definition}

\begin{tabular}{|l|l|}
\hline Name & Definition \\
\hline Day Type & $\begin{array}{l}\text { peak (the average of the three days of the month with the biggest load), week } \\
\text { (the remaining work days), or weekend }\end{array}$ \\
\hline Season & summer (May through September, inclusive) or winter (the remaining months) \\
\hline Period & $\begin{array}{l}\text { on-peak (hours of the day } 1100 \text { through 1800, inclusive, during summer } \\
\text { months only), mid-peak (0600 through } 1000 \text { and } 1900 \text { through } 2200 \text { during the } \\
\text { summer, and 0600 through 2200 during the winter), or off-peak (0100 through } \\
0500 \text { and 2300 through 2400 during all months) }\end{array}$ \\
\hline
\end{tabular}

\section{Customer Data}

\begin{tabular}{|l|l|}
\hline Name & Description \\
\hline Cload $_{m, t, h}$ & customer load in $\mathrm{kW}$ during hour $h$, day type $t$, and month $m$. \\
\hline
\end{tabular}

\section{Market Data}

\begin{tabular}{|l|l|}
\hline Name & Description \\
\hline RTPower $_{s, p}$ & $\begin{array}{l}\text { regulated demand charge under the default tariff for season } s \text { and period } p \\
(\$ / \mathrm{kW})\end{array}$ \\
\hline RTEnergy $_{m, t, h}$ & $\begin{array}{l}\text { regulated tariff for energy purchases during hour } h, \text { type of day } t \text {, and month } m \\
(\$ / \mathrm{kWh})\end{array}$ \\
\hline RTCCharge & regulated tariff customer charge $(\$)$ \\
\hline RTFCharge & regulated tariff facilities charge $(\$ / \mathrm{kW})$ \\
\hline CTax & tax on carbon emissions $(\$ / \mathrm{kg})$ \\
\hline MktCRate carbon emissions rate from marketplace generation $(\mathrm{kg} / \mathrm{kWh})$ \\
\hline$I E M_{m, t, h}$ & IEM price during hour $h$, type of day $t$, and month $m(\$ / \mathrm{kWh})$ \\
\hline
\end{tabular}

\section{Distributed Energy Resource Technologies Information}

\begin{tabular}{|c|c|}
\hline Name & Description \\
\hline$D E R \operatorname{maxp}{ }_{i}$ & nameplate power rating of technology $i(\mathrm{~kW})$ \\
\hline DERlifetime $_{i}$ & expected lifetime of technology $i$ (a) \\
\hline DERcapcost $_{i}$ & overnight capital cost of technology $i(\$ / \mathrm{kW})$ \\
\hline DEROMfix & fixed annual operation and maintenance costs of technology $i(\$ / \mathrm{kW})$ \\
\hline DEROMvar $_{i}$ & variable operation and maintenance costs of technology $i(\$ / \mathrm{kWh})$ \\
\hline DERhours $_{i}$ & $\begin{array}{l}\text { maximum number of hours technology } i \text { is permitted to operate during the year } \\
\text { (h) }\end{array}$ \\
\hline CRate $_{i}$ & carbon emissions rate from DER technology $i(\mathrm{~kg} / \mathrm{kWh})$ \\
\hline DERCostkWh & production cost of technology $i(\$ / \mathrm{kWh})$ \\
\hline
\end{tabular}




\begin{tabular}{|l|l|}
\hline Name & Description \\
\hline IntRate & $\begin{array}{l}\text { interest rate on DER investments }(\%) \\
\text { disco non-commodity revenue neutrality } \operatorname{adder}^{6}(\$ / \mathrm{kWh})\end{array}$ \\
\hline FixRate & fixed energy rate $(\$ / \mathrm{kWh})$ applied in some cases ${ }^{7}$ \\
\hline Solar $_{m, h}$ & $\begin{array}{l}\text { average fraction of maximum solar insolation received }(\%) \text { during hour } h \text { and } \\
\text { month } m\end{array}$ \\
\hline StandbyC & $\begin{array}{l}\text { standby charge in } \$ / \mathrm{kW} / \text { month that SDG\&E currently applies to its customers } \\
\text { with autonomous generation }\end{array}$ \\
\hline
\end{tabular}

\subsubsection{Variables}

\begin{tabular}{|l|l|}
\hline Name & Description \\
\hline InvGen $_{i}$ & number of units of the $i$ technology installed by the customer \\
\hline GenL $_{i, m, t, h}$ & $\begin{array}{l}\text { generated power by technology } i \text { during hour } h, \text { type of day } t, \text { and month } m \text { to } \\
\text { supply the customer's load }(\mathrm{kW})\end{array}$ \\
\hline DRLoad $_{m, t, h}{ }^{8}$ & $\begin{array}{l}\text { residual customer load (purchased power from the distribution company by the } \\
\text { customer) during hour } h, \text { type of day } t, \text { and month } m(\mathrm{~kW})\end{array}$ \\
\hline
\end{tabular}

\subsubsection{Problem Formulation}

There are two slightly different problems to be solved depending on how the $\mu$ Grid acquires the residual electricity that it needs beyond its self-generation:

1. Buying that power from the distribution company (SDG\&E) at the regulated tariff; or

2. Purchasing power at the IEM price plus an adder that would cover the non-commodity cost of delivering electricity.

In this work, a surcharge was introduced in the form of a revenue reconciliation term that was added to the IEM price or the fixed price. This term was calculated such that, if the $\mu$ Grid's usage pattern were identical under the IEM pricing option and the regulated tariff option, the distribution company (disco) would collect identical revenue from the customer.

\subsubsection{Option 1: Buying at the Default Regulated Tariff}

The mathematical formulation of the problem follows:

$$
\begin{array}{ll}
\text { InvGen }_{i}{\text {, } \text { FenL }_{i, m, t, h}}^{\min } & \sum_{m} \text { RTFCharge } \cdot \max \left(\text { DRLoad }_{m, t, h}\right)+\sum_{m} \text { RTCCharge } \\
& +\sum_{s} \sum_{m \in s} \sum_{p} \text { RTPower }_{s, p} \cdot \max \left(\text { DRLoad }_{m,(t, h) \in p}\right)
\end{array}
$$

\footnotetext{
${ }^{6}$ This value is added to the IEM price when the customer buys its power directly to the wholesale market. The DiscoER compensates the distribution company (disco) for transporting the electricity purchased from the IEM to the customer.

${ }^{7}$ If the model user selects this option the customer always buy its energy at the same price.

${ }^{8}$ Only the three first variables are decision ones. This fourth one (power purchased from the distribution company) could be expressed as a relationship between the second and third variables. However, for the sake of the model's clarity, it has been maintained.
} 


$$
\begin{aligned}
& +\sum_{m} \sum_{t} \sum_{h} \text { DRLoad }_{m, t, h} \cdot\left(\text { RTEnergy }_{m, t, h}+\text { CTax } \cdot \text { MktCRate }\right) \\
& +\sum_{i} \sum_{m} \sum_{t} \sum_{h} \operatorname{GenL}_{i, m, t, h} \cdot \operatorname{DERCostkWh_{i}} \\
& +\sum_{i} \sum_{m} \sum_{t} \sum_{h} G{ } L_{i, m, t, h} \cdot \text { DEROMvar }_{i} \\
& +\sum_{i} \sum_{m} \sum_{t} \sum_{h} \text { GenL }_{i, m, t, h} \cdot \text { CTax } \cdot \text { CRate }_{i} \\
& +\sum_{i} \text { InvGen }_{i} \cdot\left(\text { DERcapcost }_{i}+\text { DEROMfix }_{i}\right) \cdot \text { Annuity } F \\
& +\sum_{m} \sum_{i} \operatorname{InvGen}_{i} \cdot \operatorname{DERmaxp}_{i} \cdot \operatorname{StandbyC}
\end{aligned}
$$

(1)

Subject to:

$$
\begin{aligned}
& \text { Cload }_{m, t, h}=\sum_{i} \text { GenL }_{i, m, t, h}+\text { DRLoad }_{m, t, h} \quad \forall_{m, t, h} \\
& \operatorname{GenL}_{i, m, t, h} \leq \operatorname{InvGen}_{i} \cdot \operatorname{DER} \max p_{i} \quad \forall_{i, m, t, h} \\
& \text { Annuity } F=\frac{\text { IntRate }}{\left(1-\frac{1}{\left(1+\text { IntRate }^{\text {DERlifetime }_{i}}\right.}\right)} \\
& \text { GenL }_{j, m, t, h} \leq \text { InvGen }_{j} \cdot \text { DER max } p_{j} \cdot \text { Solar }_{m, h} \forall_{m, t, h} \text { if } j \in\{P V\} \\
& \sum_{m} \sum_{t} \sum_{h} G \operatorname{CnL}_{i, m, t, h} \leq \operatorname{InvGen}_{i} \cdot \text { DER max } p_{i} \cdot \text { DERhours }_{i} \forall_{i}
\end{aligned}
$$

Equation (1) is the objective function which states that the $\mu$ Grid will try to minimize total cost, consisting of total facilities and customer charges, total monthly demand charges, total energy charges (inclusive of carbon taxes), total on-site generation fuel and O\&M costs, total on-site generation carbon taxes, total DER investment cost, and total standby charges, if applicable.

Equation (2) enforces energy balance. Equation (3) enforces the on-site generating capacity constraint. Equation (4) simply annualizes the capital cost of owning on-site generating equipment. If DER technology $j$ is a photovoltaic (PV) cell, then equation (5) constrains it to generate in proportion to the solar insolation. Finally, equation (6) places an upper limit on how many hours each type of DER technology can generate during the year. Most of the technologies are allowed to generate during all hours of the year, but diesel generators, for example, are allowed to run for only 52 hours per year according to California legislation.

\subsubsection{Option 2: Buying from Alternative Energy Providers}

The problem's mathematical formulation follows: 


$$
\begin{aligned}
& \operatorname{InvGen}_{i}, \text { GenL }_{i, m, t, h} \\
& \sum_{m} \sum_{t} \sum_{h} \text { DRLoad }_{m, t, h} \cdot\left(\text { IEM }_{m, t, h}+\text { DiscoER }+ \text { CTax } \cdot \text { MktCRate }\right) \\
& +\sum_{i} \sum_{m} \sum_{t} \sum_{h} \operatorname{GenL}_{i, m, t, h} \cdot \operatorname{DERCostkWh_{i}} \\
& +\sum_{i} \sum_{m} \sum_{t} \sum_{h} G \operatorname{enL}_{i, m, t, h} \cdot \text { DEROMvar }_{i} \\
& +\sum_{i} \sum_{m} \sum_{t} \sum_{h} \text { GenL }_{i, m, t, h} \cdot \text { CTax }_{\text {CRate }}
\end{aligned}
$$

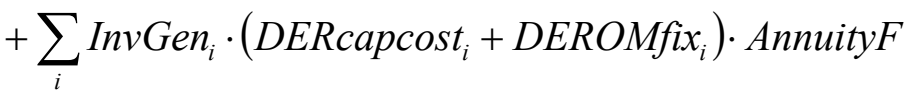

$$
\begin{aligned}
& +\sum_{m} \sum_{i} \operatorname{InvGen}_{i} \cdot \operatorname{DERmaxp}_{i} \cdot \operatorname{StandbyC}
\end{aligned}
$$

(1a)

Subject to:

Equations (2) through (6)

This formulation differs only in the objective function, equation (1a), which now charges the IEM price for each hourly time step plus the non-commodity revenue neutrality adder and the carbon tax. Note that the same mathematical formulation can be used if the model user wants to simulate a fixed price for all customer energy purchases. In that case, all IEM hourly prices are simply set to the fixed desired value.

\section{Customer Description and Input Data}

\subsection{Load Shape Data}

DER-CAM is run for a hypothetical $\mu$ Grid composed of eight typical Southern California commercial electricity customers acting as one (a supermarket, an office, a sit-down restaurant, a fast food restaurant, a delicatessen, a department store, a retail store, and a warehouse store). An available archived set of commercial hourly load data that had been collected by Southern California Edison (SCE) in 1988-1989 (SCE 1989), (Akbari 1993) were used as the basis for the loads for the hypothetical customers.

The hourly annual data are organized into the day-types peak, weekday, and weekend as described in Section 2.4.1.1. A sample load profile is presented in Figure 1. 


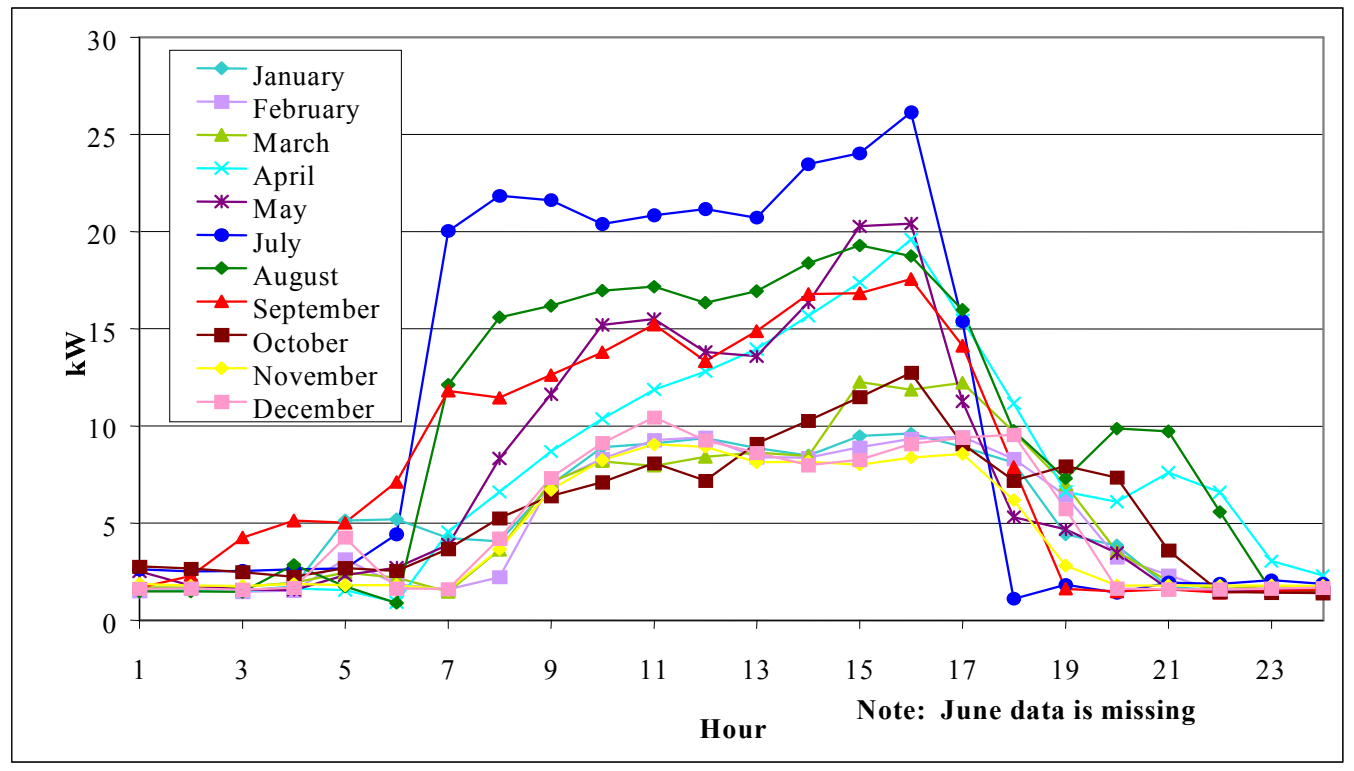

Figure 1. Office Monthly Peak Load

Table 1. Illustrates the composition of the $\mu$ Grid as chosen for this a nalysis.

Table 1. $\mu$ Grid Summary

\begin{tabular}{|c|c|c|c|c|c|c|c|c|}
\hline 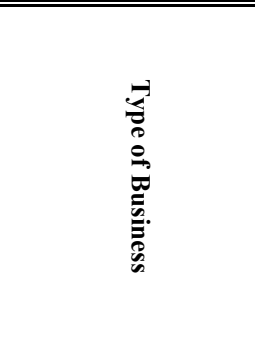 & 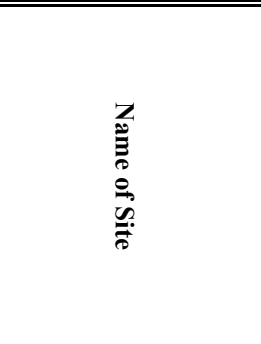 & 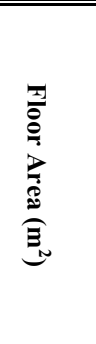 & 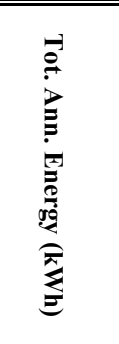 & 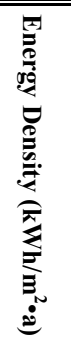 & 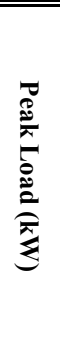 & 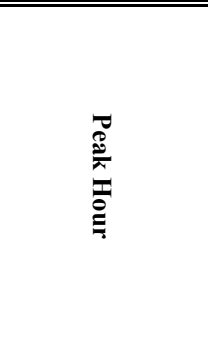 & 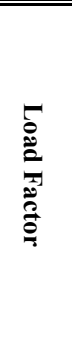 & 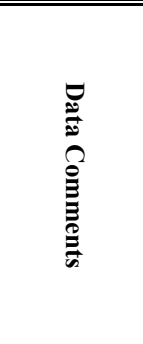 \\
\hline 1. Supermarket & Dangerway & 1,536 & $1,708,581$ & 1,112 & 255 & Sept 15:00 & $76 \%$ & complete \\
\hline 2. Office & Great Vistas Real Estate & 223 & 40,269 & 181 & 26 & July 16:00 & $18 \%$ & june missing \\
\hline 3. Sitdown Restaurant & Nan Hideaway & 1,003 & 529,231 & 528 & 110 & Sept 17:00 & $55 \%$ & complete \\
\hline 4. Fast Food Restaurant & Burger Queen & 339 & 487,973 & 1,439 & 100 & July $12: 00$ & $55 \%$ & complete \\
\hline 5. Deli Restaurant & Sub Safe Harbor & 674 & 199,553 & 296 & 56 & July $13: 00$ & $41 \%$ & complete \\
\hline 6. Department Store & Spacy's & 6,466 & $1,459,949$ & 226 & 309 & Sept 12:00 \& 15:00 & $54 \%$ & complete \\
\hline 7. Retail Store & Drum Buster Stereo & 1,347 & 263,367 & 196 & 81 & July 13:00-16:00 & $37 \%$ & complete \\
\hline 8. Warehouse Store & Ram's Club & $\mathrm{N} / \mathrm{A}$ & $1,821,001$ & $\mathrm{~N} / \mathrm{A}$ & 299 & July $15: 00$ & $69 \%$ & complete \\
\hline . Total Microgrid & Microgrid Oaks Mall & $11,588^{*}$ & $6,370,206$ & $405^{*}$ & 1253 & July $14: 00$ & $58 \%$ & june missing \\
\hline
\end{tabular}

$*$ not including warehouse since floor area data is not available

\subsection{SDG\&E Tariff and IEM Prices}

$\mu$ Grid s purchasing electricity from their disco are assumed to do so under established 2000 tariffs. In this study, three publicly available tariff rates for commercial customer types are used (see Table 2), depending on the size of the customer's peak load. For each tariff type, a monthly-ratcheted demand charge and an energy charge are imposed and vary seasonally. 
The load periods (on-peak, mid-peak, and off-peak) are defined differently under each season. In addition, a fixed charge per customer per month is levied (see Table 3). ${ }^{9}$

Table 2. SDG\&E AL-TOU (General Service Time-of-Use) Tariff Information

\begin{tabular}{|l|l|l|l|}
\hline Season & $\begin{array}{l}\text { Load } \\
\text { Period }\end{array}$ & $\begin{array}{l}\text { Demand } \\
\text { Charge } \\
\text { (US\$/kW) }\end{array}$ & $\begin{array}{l}\text { Energy } \\
\text { Charge } \\
\text { (US\$/kWh) }\end{array}$ \\
\hline summer & on-peak & 9.00 & 0.21262 \\
\hline summer & mid-peak & 5.78 & 0.11851 \\
\hline summer & off-peak & 5.78 & 0.07442 \\
\hline winter & on-peak & 0.00 & 0.00000 \\
\hline winter & mid-peak & 5.78 & 0.11281 \\
\hline winter & off-peak & 5.78 & 0.06995 \\
\hline
\end{tabular}

Table 3. SDG\&E AL-TOU Fixed Customer Charges

\begin{tabular}{|l|l|}
\hline $\begin{array}{l}\text { Customer } \\
\text { Charge } \\
\text { (US\$/month) }\end{array}$ & $\begin{array}{l}\text { Stand-by Charge } \\
\text { (US\$/kW/month) }\end{array}$ \\
\hline 43.50 & 0.00 \\
\hline
\end{tabular}

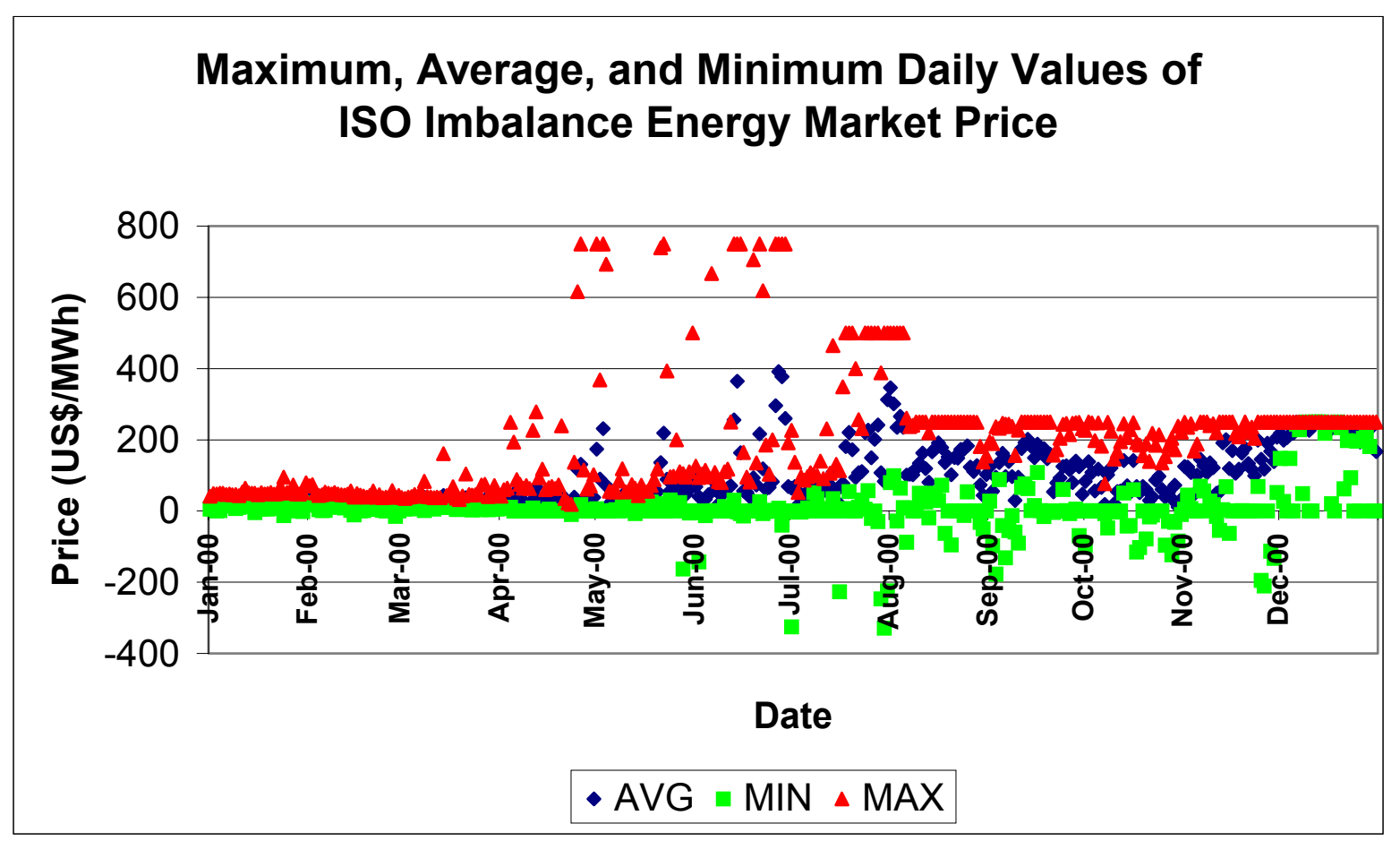

Figure 2. California Independent System Operator (CAISO) IEM Price Summary for 2000

For California, the competitive electricity price generally refers to the CAISO IEM price, essentially a spot market for electricity. Figure 2. summarizes market prices for 2000. In general, the IEM prices were within their historical ranges (i.e., less than US\$50/MWh) for the first half of the year. By July 2000, however, the combination of supply constraints,

\footnotetext{
${ }^{9}$ In the U.S. peak power charges are usually called demand charges.
} 
burgeoning natural gas prices (which is burned by most generators to produce electricity), and inelastic consumer demand drove the IEM price to the artificially imposed price caps. ${ }^{10}$

\subsection{Generating Technology Data}

The generating technologies available to the customers are listed in Table 4. along with their operating characteristics. The technologies beginning with labels $M T$ are microturbines, manufactured by Capstone. PAFC is a phosphoric acid fuel cell $(F C$ ) made by ONSI (now known as UTC Fuel Cells).

Those beginning with $D E-K$ and $D E-C$ are diesel backup generators manufactured by Katolight and Cummins/Onan, respectively. The rest of the technologies are various brands of Katolight natural gas backup generators (labeled by $G A-K)$ and photovoltaic systems $(P V)$. The solar insolation data, which indicate the fraction of maximum historical solar insolation received in the Southern California test area, are provided by the National Renewable Energy Laboratory (NREL, http://www.nrel.gov). ${ }^{11}$ Figure 3. illustrates how available sunlight changes throughout the year and affects PV operation decisions. This is accounted for by equation (5) in Sections 2.4.2.1 and 2.4.2.2.

Table 4. DER Technology Characteristics

\begin{tabular}{|c|c|c|c|c|c|c|c|c|}
\hline Technology & $\begin{array}{c}\text { Name- } \\
\text { plate } \\
(\mathbf{k W})\end{array}$ & $\begin{array}{l}\text { Lifetime } \\
\text { (a) }\end{array}$ & $\begin{array}{c}\text { Turnkey Cost } \\
(\mathrm{US} \$ / \mathbf{k W})\end{array}$ & $\begin{array}{c}\text { OMFix } \\
\text { (US\$/kW/a) }\end{array}$ & $\begin{array}{c}\text { OMVar } \\
\text { (US\$/kWh) }\end{array}$ & $\begin{array}{c}\text { Heat Rate } \\
(\mathrm{kJ} / \mathrm{kWh})\end{array}$ & Source & Fuel \\
\hline MTL-C-30 & 30 & 12.5 & 1333 & 119 & 0 & 12,186 & $\overline{\mathrm{SCE}}$ & natural gas \\
\hline MTH-C-30 & 30 & 12.5 & 1333 & 119 & 0 & 12,186 & SCE & natural gas \\
\hline PAFC-O-200 & 200 & Proprietary & Proprietary & Proprietary & Proprietary & Proprietary & Proprietary & natural gas \\
\hline DE-K-15 & 15 & 12.5 & 2257 & 26.5 & 0.000033 & 18,288 & Manu & diesel \\
\hline DE-K-30 & 30 & 12.5 & 1290 & 26.5 & 0.000033 & 11,887 & Manu & diesel \\
\hline DE-K-60 & 60 & 12.5 & 864 & 26.5 & 0.000033 & 11,201 & Manu & diesel \\
\hline DE-K-105 & 105 & 12.5 & 690 & 26.5 & 0.000033 & 10,581 & Manu & diesel \\
\hline DE-K-200 & 200 & 12.5 & 514 & 26.5 & 0.000033 & 11,041 & Manu & diesel \\
\hline DE-K-350 & 350 & 12.5 & 414 & 26.5 & 0.000033 & 10,032 & Manu & diesel \\
\hline DE-K-500 & 500 & 12.5 & 386 & 26.5 & 0.000033 & 10,314 & Manu & diesel \\
\hline DE-C-7 & 7.5 & 12.5 & 627 & 26.5 & 0.000033 & 10,458 & Manu & diesel \\
\hline DE-C-20 & 20 & 12.5 & 1188 & 26.5 & 0.000033 & 12,783 & Manu & diesel \\
\hline DE-C-40 & 40 & 12.5 & 993 & 26.5 & 0.000033 & 11,658 & Manu & diesel \\
\hline DE-C-100 & 100 & 12.5 & 599 & 26.5 & 0.000033 & 10,287 & Manu & diesel \\
\hline DE-C-200 & 200 & 12.5 & 416 & 26.5 & 0.000033 & 9,944 & Manu & diesel \\
\hline DE-C-300 & 300 & 12.5 & 357 & 26.5 & 0.000033 & 10,287 & Manu & diesel \\
\hline DE-C-500 & 500 & 12.5 & 318 & 26.5 & 0.000033 & 9,327 & Manu & diesel \\
\hline GA-K-25 & 25 & 12.5 & 1730 & 26.5 & 0.000033 & 15,596 & Manu & natural gas \\
\hline GA-K-55 & 55 & 12.5 & 970 & 26.5 & 0.000033 & 12,997 & Manu & natural gas \\
\hline GA-K-100 & 100 & 12.5 & 833 & 26.5 & 0.000033 & 15,200 & Manu & natural gas \\
\hline GA-K-215 & 215 & 12.5 & 1185 & 26.5 & 0.000033 & 13,157 & Manu & natural gas \\
\hline GA-K-500 & 500 & 12.5 & 936 & 26.5 & 0.000033 & 12,003 & Manu & natural gas \\
\hline PV-5 & 5 & 20 & 8650 & 14.3 & 0 & 0 & $\begin{array}{c}\text { Jeff Oldman, Real } \\
\text { Goods }\end{array}$ & sun \\
\hline PV-20 & 20 & 20 & 7450 & 14.3 & 0 & 0 & $\begin{array}{l}\text { Jeff Oldman, Real } \\
\text { Goods }\end{array}$ & sun \\
\hline PV -50 & 50 & 20 & 6675 & 12 & 0 & 0 & $\begin{array}{l}\text { Jeff Oldman, Real } \\
\text { Goods }\end{array}$ & sun \\
\hline PV-100 & 100 & 20 & 6675 & 11 & 0 & 0 & $\begin{array}{l}\text { Jeff Oldman, Real } \\
\text { Goods }\end{array}$ & sun \\
\hline
\end{tabular}

\footnotetext{
${ }^{10}$ These were first US\$750/MWh, but were later lowered to US\$250/MWh.

${ }^{11}$ The "peak" insolation refers to the historically accepted peak value of $1050 \mathrm{Wh} / \mathrm{m}^{2}$, which is less than the peak value in the data set $\left(1303 \mathrm{Wh} / \mathrm{m}^{2}\right)$. These data are for San Diego, CA (latitude N 32 44, longitude W 11710 , and elevation $9 \mathrm{~m}$ ) from 1990. Furthermore, the peak rating is under certain test conditions, and field performance can exceed the test condition.
} 


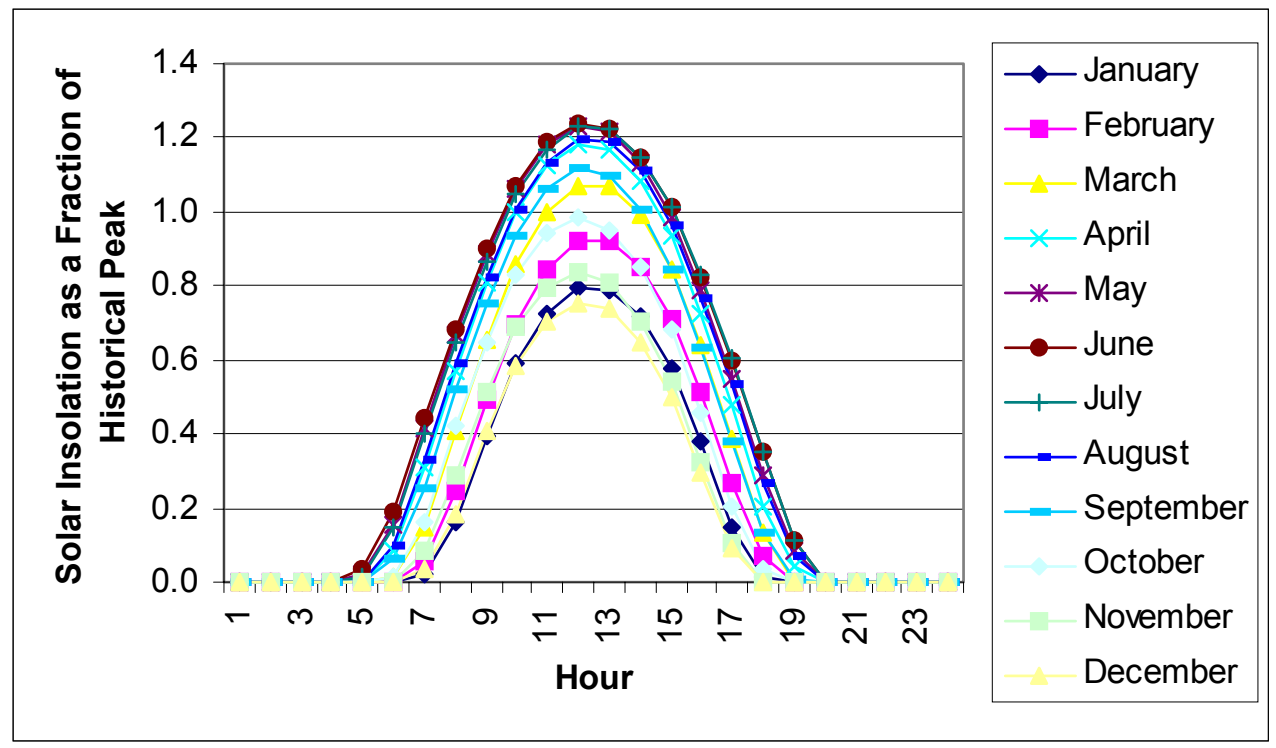

Figure 3. Solar Insolation as a Fraction of Historical Peak Value Received in the Southern California Test Area

\subsection{Fuel Data}

The fuel prices and carbon emissions data are summarized by Table 5. In order to obtain the actual carbon emissions (in $\mathrm{kg} / \mathrm{kWh}$ ) for any particular technology, simply multiply the heat rate of the technology (from Table 4) by the appropriate carbon emissions rate of the corresponding fuel. For electricity that is generated offsite, i.e., electricity purchased from the IEM or SDG\&E, the average annual carbon emissions rate is $0.13 \mathrm{~kg} / \mathrm{kWh}$. Note that while both the natural gas and diesel prices varied considerably throughout 2000, it is assumed that the $\mu$ Grid hedges against such price volatility by signing long-term contracts. Hence, it pays a constant price for fuel throughout the year, which is equal to the mean price. In future work, we anticipate incorporating the seasonal variation in fuel prices; but here we abstract from this feature to focus on electricity prices and generation.

Table 5. Fuel Data

\begin{tabular}{|lll|}
\hline Fuel & $\begin{array}{l}\text { Price } \\
(\mathbf{U S} \mathbf{\$} / \mathbf{k J})\end{array}$ & $\begin{array}{l}\text { Carbon Emissions Rate } \\
(\mathbf{k g} / \mathbf{k J})\end{array}$ \\
\hline $\begin{array}{l}\text { Sun } \\
\text { Natural }\end{array}$ & 0.00 & 0.00 \\
Gas & $8.25 \times 10^{-6}$ & $1.3715 \times 10^{-5}$ \\
Diesel & $8.46 \times 10^{-6}$ & $1.8909 \times 10^{-5}$ \\
\hline
\end{tabular}

\subsection{Carbon Costs}

It is likely that a carbon emissions market will emerge in the next few years, starting in industrialized countries that have shown active interest in fulfilling the Kyoto climate change protocol. The market mechanisms will ensure that the most cost-effective options are selected to mitigate carbon emissions.

Although there is still considerable uncertainty in the magnitude of carbon costs, recent studies in the USA and in the European Union indicate a large savings potential, both in the 
supply- and demand-side, with a tax of less than US\$100 per metric ton $(\mathrm{t})$ of carbon. In the European Climate Change Program, it was shown that the European Union could reduce its carbon emissions in 2010 by $8 \%$, using technology options under a tax of US\$70/t (see E.C. 2001).

\section{Results}

In this chapter, we examine the implications that a carbon tax has on DER investment and carbon emissions. In order to insure that our analysis is robust, it is performed under various regulatory and economic conditions, summarized by Table 6 . We find that a carbon tax generally stimulates DER investment, especially if additional subsidies are given for the installation of "green" (or, environmentally friendly) technologies, such as PVs and FCs. In turn, this greater DER investment in "green" technologies enables a reduction in operating costs for the $\mu$ Grid relative to purchasing electricity from the macrogrid.

Similarly, if "green" subsidies are present, a carbon tax of US\$500/t is enough to reduce carbon emissions by over a third relative to the case with no carbon tax. Absent such subsidies, comparable reductions in emissions are possible only for higher levels of carbon tax. In order to provide a basis for comparison, we determine both the minimum and maximum levels of carbon emissions that could be produced. While the carbon emitted by the $\mu \mathrm{Grid}$ in our model is not driven to the minimum level possible; we find that a carbon tax of US\$500/t along with "green" subsidies is enough to reduce emissions to less than $75 \%$ of the maximum level.

Table 6. Operating Scenarios for Purchasing Electricity

\begin{tabular}{|l|l|}
\hline $\begin{array}{l}\text { Operating Scenarios and } \\
\text { Sensitivities }\end{array}$ & Description \\
\hline Base (IEM) & $\begin{array}{l}\text { In this scenario, the } \mu \text { Grid can buy all of its electricity } \\
\text { requirements at the IEM price. However, it also has to } \\
\text { pay an extra fee in order to achieve revenue neutrality for } \\
\text { the disco (compared with the tariff scenario, described } \\
\text { next). This solves the model in Section } 2.4 .2 .2 .\end{array}$ \\
\hline Disco (SDG\&E) & $\begin{array}{l}\text { In this scenario, the } \mu \text { Grid buys all of its electricity from } \\
\text { the disco at an established tariff structure. This solves the } \\
\text { model in Section 2.4.2.1. }\end{array}$ \\
\hline $25 \%$ Subsidy & $\begin{array}{l}\text { Same as "base," but all "green" technologies (such as fuel } \\
\text { cells and photovoltaics) are given a } 25 \% \text { state subsidy } \\
\text { towards their turnkey costs. }\end{array}$ \\
\hline $50 \%$ Subsidy & $\begin{array}{l}\text { Same as "25 \% subsidy," but now the subsidy is } \\
\text { increased to cover } 50 \% \text { of the turnkey costs. }\end{array}$ \\
\hline
\end{tabular}

\subsection{Effect of Carbon Tax on Generation}

Intuitively, the effect of a carbon tax would be to stimulate the adoption of "greener" generation technologies since they emit less carbon per $\mathrm{kWh}$ of electricity produced. Within the context of our $\mu$ Grid model with DER options, such a tax encourages the $\mu$ Grid to increase investment in "green" DER technologies, such as PVs. This transition, however, usually does not occur until the carbon tax is hundreds of dollars per metric ton (see Figure 4 to Figure 8). Indeed, for all cases except when "green" technologies receive a 50\% turnkey cost subsidy, the presence of a carbon tax is not enough incentive for the $\mu$ Grid to adopt "green" technologies unless the carbon tax is greater than US\$400/t. For values of the carbon 
tax lower than this value, the $\mu$ Grid finds it cheaper to meet its electricity needs through the macrogrid (either the IEM or the disco SDG\&E) and DER technologies that use natural gas. It is only in the $50 \%$ "green" technologies subsidy case that the $\mu$ Grid finds it attractive to install "green" DER technologies such as PVs for low values of the carbon tax. In fact, it installs a small PV system even without a carbon tax.

In order to assess the effect of the carbon tax on actual onsite energy generation, the fraction of electricity that the $\mu$ Grid produces with DER in the four cases is shown by Figure 9. to Figure 12. Again, the general trend is that the fraction of energy produced onsite decreases slightly until the carbon tax is high enough to make installation of PVs economically attractive and spurs more onsite generation. This transition towards PV adoption occurs for lower levels of carbon tax in the 50\% "green" technologies subsidy case. Nevertheless, the fraction of energy generated onsite in all cases starts off at about $50 \%$ and increases to $60 \%$ with the carbon tax. The only case that deviates from such behavior is the disco case, in which the evening tariff rate is low enough to deter usage of DER technologies during offpeak hours. Hence, because the PVs cannot operate during these hours, the $\mu$ Grid does not reduce its dependence on the macrogrid in the disco case.

A corollary effect of the carbon tax is that it enables the $\mu$ Grid to reduce its costs through DER investment. In the same figures, we plot on a secondary axis the percentage cost savings that accrue to the $\mu$ Grid due to its having the option to invest in DER technologies. In other words, we compare the costs of using only the macrogrid with the costs of supplementing macrogrid purchases with DER investment. For all cases, the cost savings from having the option to install DER decrease until the carbon tax reaches a critical value. This is because for low levels of carbon taxation, the $\mu$ Grid increases its macrogrid purchases. It is not until the carbon tax is high enough that PV installation is cost-effective, and thereby, reduces the $\mu$ Grid 's reliance on the macrogrid. This effect is illustrated by Table 7, in which the fraction of carbon emissions from the macrogrid increases with the carbon tax even as the fraction of energy generated by it decreases. While the carbon tax makes the $\mu$ Grid better off in a relative sense (i.e., compared to the case in which it is solely reliant on the macrogrid), it, nevertheless, results in absolute cost increases. Figure 13. indicates that for all cases, a carbon tax on the order of US $\$ 1000 / t$ is enough to double the $\mu$ Grid 's costs.

The effect of the carbon tax is to encourage investment in "green" DER technologies. In general, such adoption also results in the $\mu$ Grid's satisfying a larger fraction of its energy needs through onsite generation than in the case without a carbon tax. Furthermore, the option to install DER technologies enables the $\mu$ Grid to reduce costs by about $20 \%$ from the situation in which no DER technologies are available. These benefits, however, don't begin to accrue until the carbon tax exceeds US\$400/ton. Only when substantial (e.g., 50\%) turnkey cost subsidies are given to "green" technologies is it immediately attractive for the $\mu \mathrm{Grid}$ to install DER technologies in response to carbon taxation. 


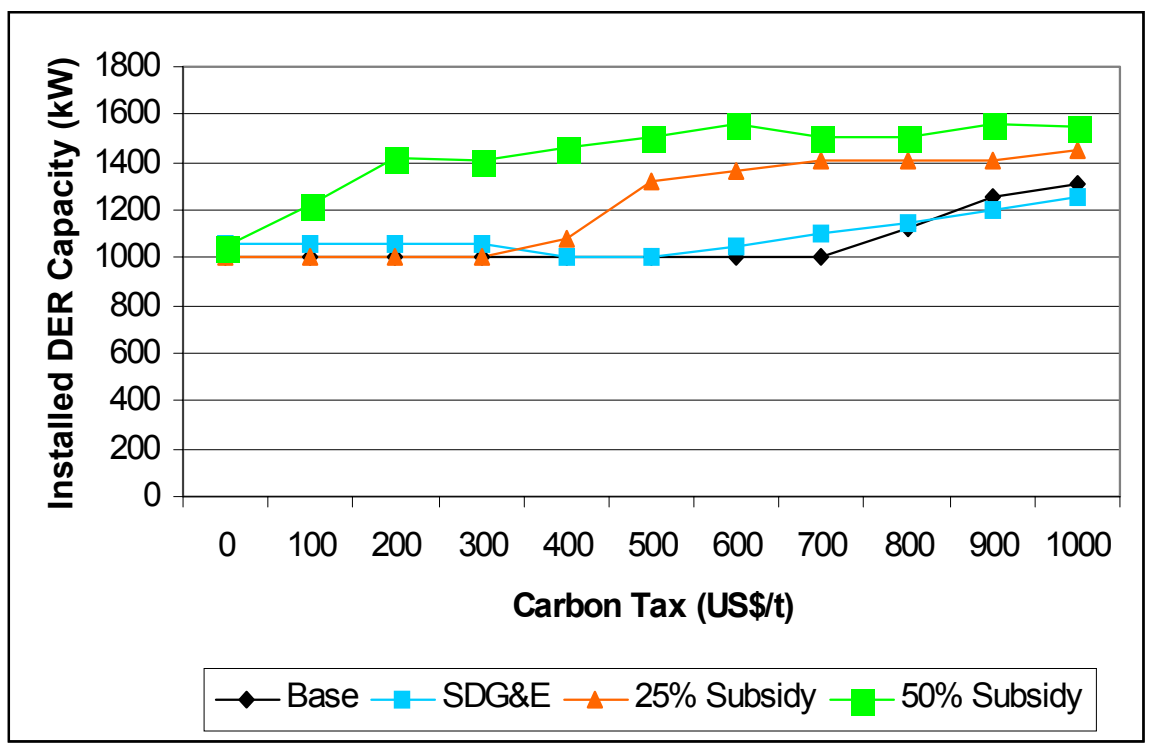

Figure 4. Installed DER Capacity

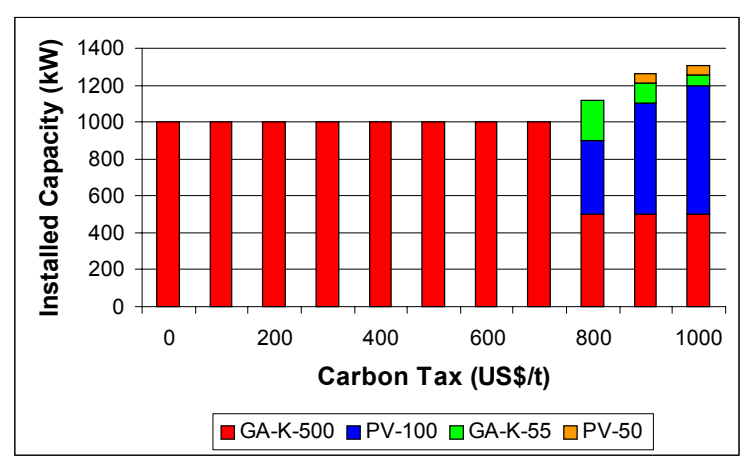

Figure 5. Installed DER Technologies for the Base Case

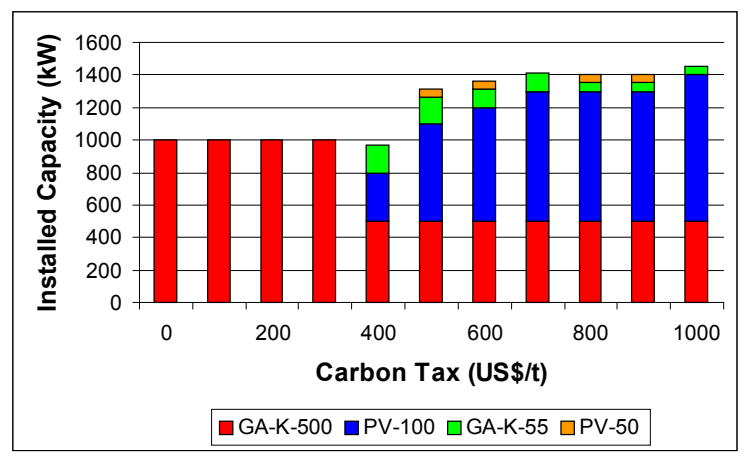

Figure 7. Installed DER Technologies for the $25 \%$ Subsidy Case

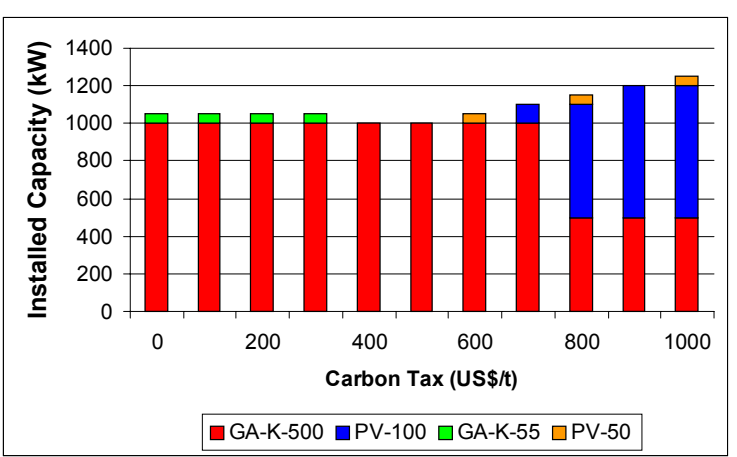

Figure 6. Installed DER Technologies for the Disco SDG\&E Tariff Case

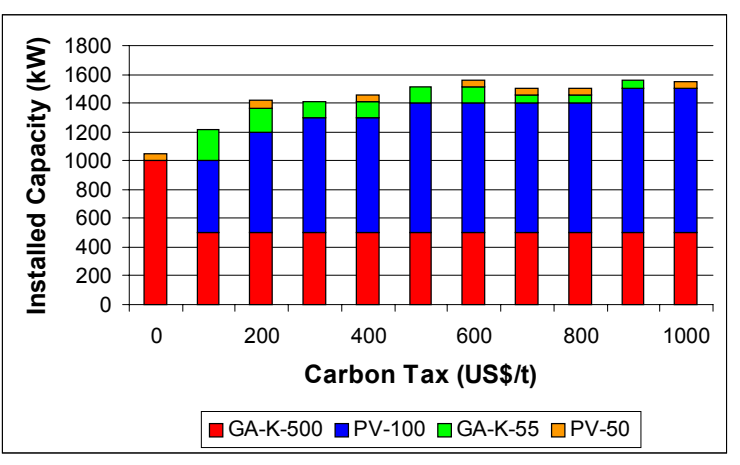

Figure 8. Installed DER Technologies for the $50 \%$ Subsidy Case 
Table 7. Percentage of Carbon Emissions from Macrogrid

\begin{tabular}{|l|l|l|l|l|}
\hline $\begin{array}{l}\text { Carbon Tax } \\
\text { (US\$/t) }\end{array}$ & Base Case & SDG\&E Case & $\mathbf{2 5 \%}$ Subsidy & $\mathbf{5 0 \%}$ Subsidy \\
\hline 0 & $44 \%$ & $42 \%$ & $44 \%$ & $45 \%$ \\
\hline 100 & $45 \%$ & $44 \%$ & $45 \%$ & $59 \%$ \\
\hline 200 & $46 \%$ & $45 \%$ & $46 \%$ & $71 \%$ \\
\hline 300 & $47 \%$ & $46 \%$ & $47 \%$ & $76 \%$ \\
\hline 400 & $48 \%$ & $46 \%$ & $55 \%$ & $79 \%$ \\
\hline 500 & $48 \%$ & $47 \%$ & $70 \%$ & $82 \%$ \\
\hline 600 & $48 \%$ & $48 \%$ & $75 \%$ & $84 \%$ \\
\hline 700 & $49 \%$ & $50 \%$ & $79 \%$ & $87 \%$ \\
\hline 800 & $52 \%$ & $65 \%$ & $71 \%$ & $75 \%$ \\
\hline 900 & $57 \%$ & $61 \%$ & $65 \%$ & $70 \%$ \\
\hline 1000 & $60 \%$ & $62 \%$ & $66 \%$ & $71 \%$ \\
\hline
\end{tabular}

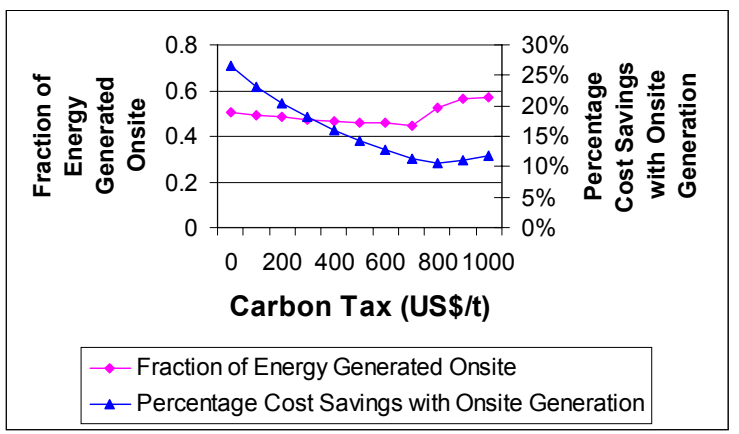

Figure 9. Effect of Carbon Tax on Energy Generation and Costs for the Base Case

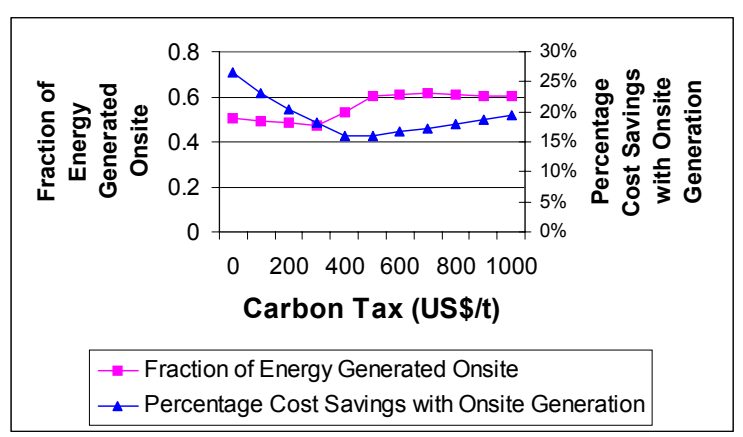

Figure 11. Effect of Carbon Tax on Energy Generation and Costs for the $25 \%$ Subsidy Case

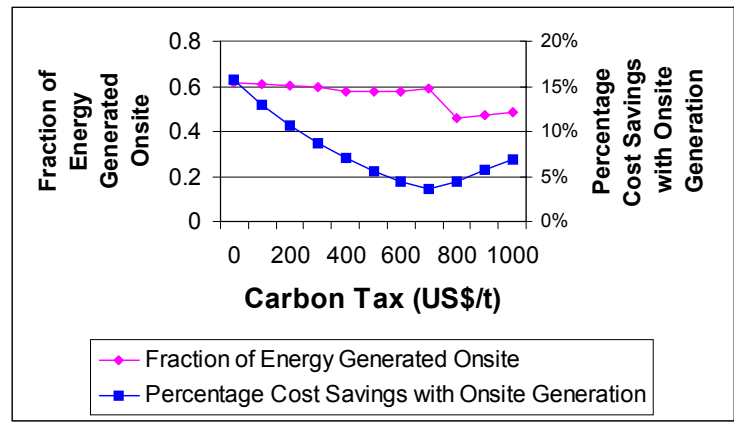

Figure 10. Effect of Carbon Tax on Energy Generation and Costs for the Disco SDG\&E Tariff Case

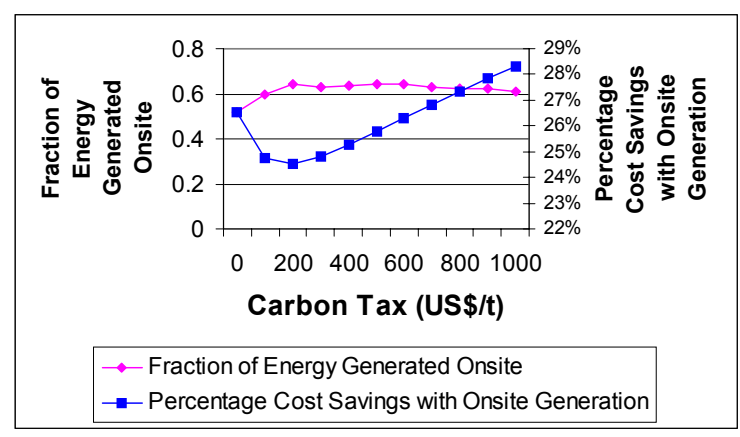

Figure 12. Effect of Carbon Tax on Energy Generation and Costs for the $50 \%$ Subsidy Case 


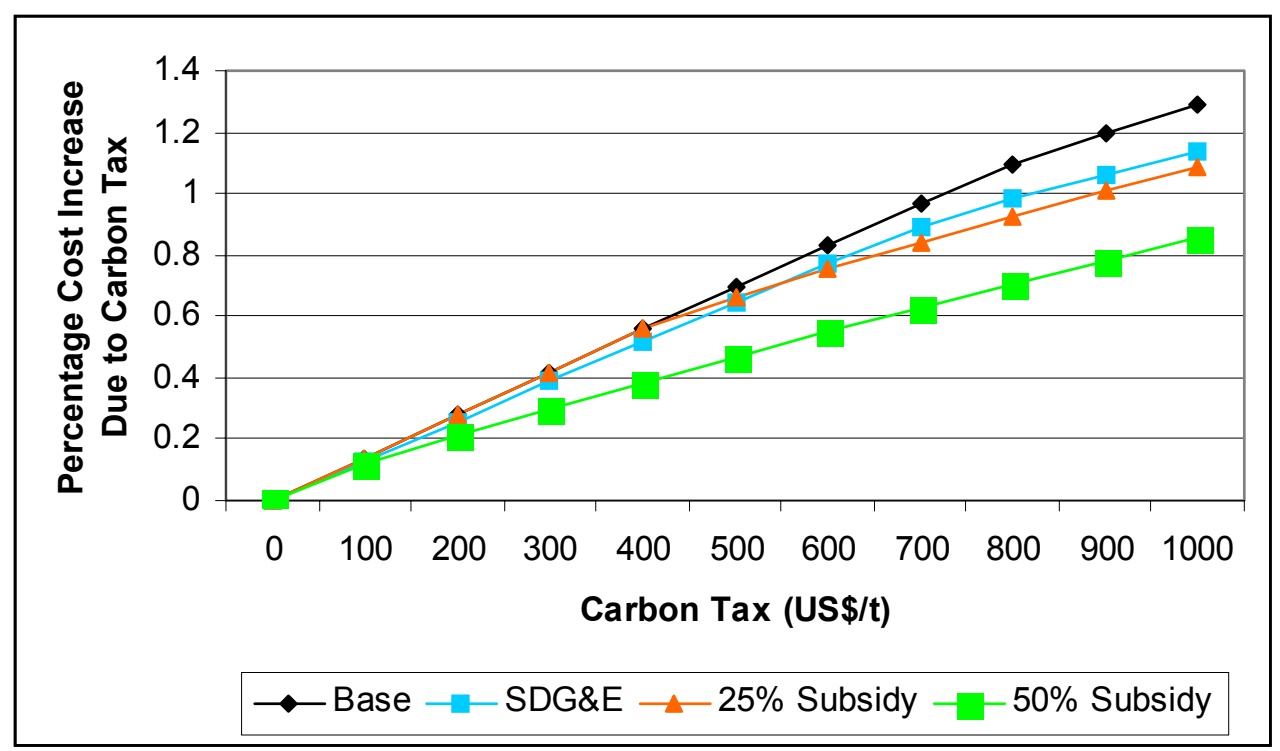

Figure 13. Percentage Cost Increase Due to Carbon Tax

\subsection{Effect of Carbon Tax on Emissions}

The effect of the carbon tax on carbon emissions is similar to its effect on DER adoption and $\mu$ Grid costs. In general, the environmental impact of a carbon tax of US $\$ 700 / t$ is to reduce cumulative carbon emissions by over $40 \%$ from a scenario with no carbon tax (see Figure 14). Although carbon taxes provide an impetus for the $\mu$ Grid to invest in ("green") DER technologies to reduce carbon emissions for carbon tax levels less than US\$500/t, they have only marginal impact. Indeed, with a macrogrid carbon emissions rate of $0.13 \mathrm{~kg} \mathrm{C} / \mathrm{kWh}^{12}$, it is not economically viable for the $\mu$ Grid to invest in DER technologies in response to carbon taxation, unless the carbon tax exceeds US\$400/t. Only for the 50\% "green" technologies subsidy case is investment in "green" DER technologies effective at low levels of carbon taxation.

In the disco tariff case, carbon emissions decrease by a greater amount than they do in the IEM case, even though a greater proportion of the $\mu$ Grid 's energy needs are met through onsite generation in the latter case. This is because the higher peak (i.e., daytime) tariff rates together with the high carbon emissions rates of conventional DER technologies encourage a migration to "green" DER technology adoption at lower levels of carbon taxation than in the IEM case. For the same level of carbon tax, the IEM peak prices are lower than the disco tariff rates, thereby delaying the adoption of "green" DER technologies and the abatement of carbon emissions.

While the carbon tax does eventually result in almost halving the level of carbon emissions, how does it compare to other carbon control policies? Here, we consider two other policies:

1. A macrogrid only (MO) policy in which the $\mu$ Grid is taxed for carbon emissions, but is not permitted to install DER technologies. In this policy, the $\mu$ Grid solves the model in Section 2.4.2.1 (or Section 2.4.2.2 if it purchases electricity from the IEM), but with InvGen $_{i}=0 \forall i$ (and therefore, with $G e n L_{i, m, t, h}=0 \forall i, m, t, h$ ).

\footnotetext{
${ }^{12}$ This compares favorably with rates of $0.16 \mathrm{~kg} \mathrm{C} / \mathrm{kWh}$ and $0.18 \mathrm{~kg} \mathrm{C} / \mathrm{kWh}$ for the most efficient natural gas and diesel DER technologies, respectively.
} 
2. A perfectly green (PG) policy in which the $\mu$ Grid is mandated to minimize its carbon emissions only instead of its combined costs. Here, the objective function is simply $\min _{{\text {InvGen }, \text { GenL } L_{i, m . t . h}}} \sum_{i} \sum_{m} \sum_{t} \sum_{h}\left(\right.$ DRLoad $_{m, t, h} \cdot$ MktCRate GenL $_{i, m, t, h} \cdot$ CRate $\left._{i}\right)$ instead of equation (1) or (1a). This is essentially a situation in which PVs supply electricity during the day, and the macrogrid provides electricity at night. As usual, DER technology investment is permitted.

In Figure 15 to Figure 18, we plot the carbon emissions from using the combined cost function (CCF), i.e., the one described by equations (1) and (1a), along with the carbon emissions under the MO and PG policies. Note that because the MO and PG policies are static, the level of carbon emissions does not vary with the carbon tax. For low levels of carbon taxation, we find that the level of carbon emissions under the CCF exceeds the carbon emissions from both the MO and PG policies. Once the carbon tax increases to about US\$500/t, carbon emissions under the CCF decline to below the MO policy levels as "green" DER technology investment becomes attractive. For the 50\% "green" technology subsidy case, this transition occurs for a lower level of taxation. After "green" DER technology is installed and used regularly, carbon emissions continue to decline. For very high levels of carbon tax, i.e., around US $\$ 1000 / t$, carbon emissions begin to approach the levels yielded by the PG policy. This decline is gradual, and even in the 50\% "green" technology subsidy case with a US\$1000/t carbon tax, carbon emissions remain one and a half times as high as they are with the PG policy.

The near halving of carbon emissions from pre-tax levels is the ultimate result of the carbon tax. This reduction, however, occurs only for relatively high levels of carbon tax as the high turnkey cost of most "green" DER technologies proves too big a barrier to their adoption. An effective methodology for reducing carbon emissions, therefore, is to provide a subsidy towards the turnkey costs of "green" technologies. Within the context of this model, the latter approach achieves the greatest reduction in carbon emissions at the lowest levels of carbon taxation.

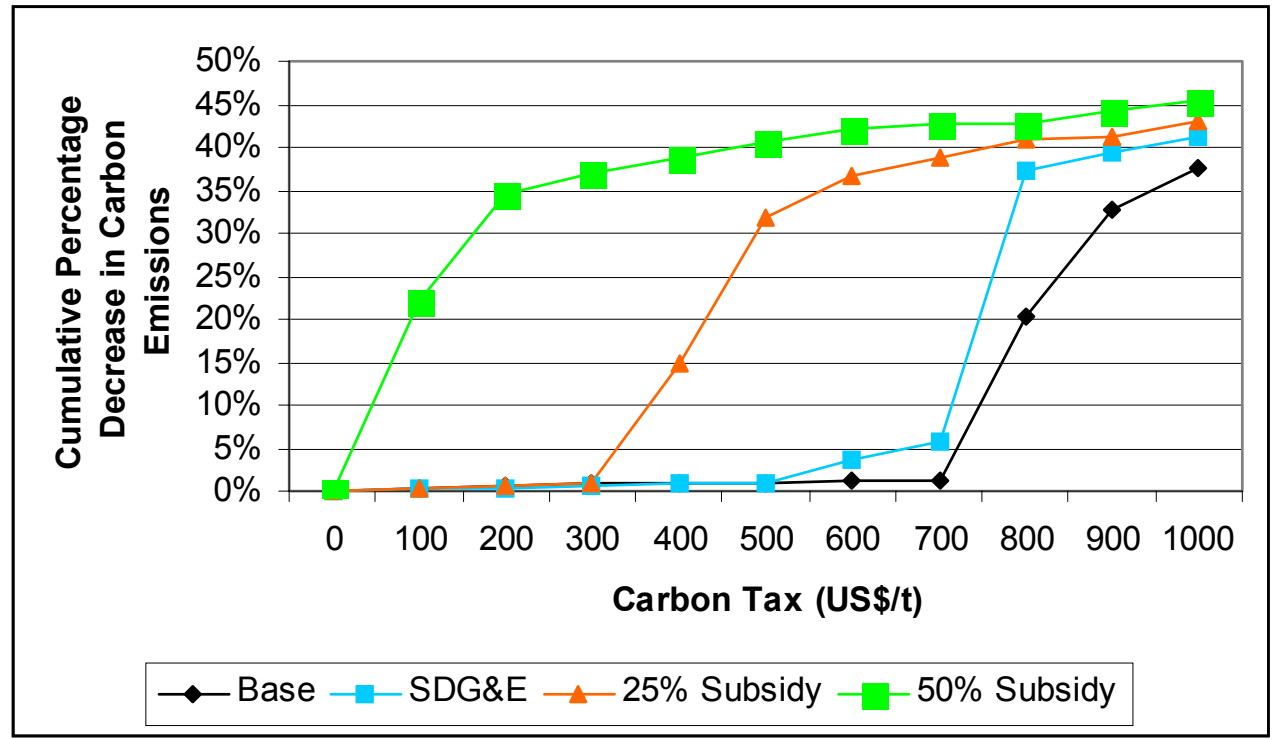

Figure 14. Cumulative Percentage Decrease in Carbon Emissions 


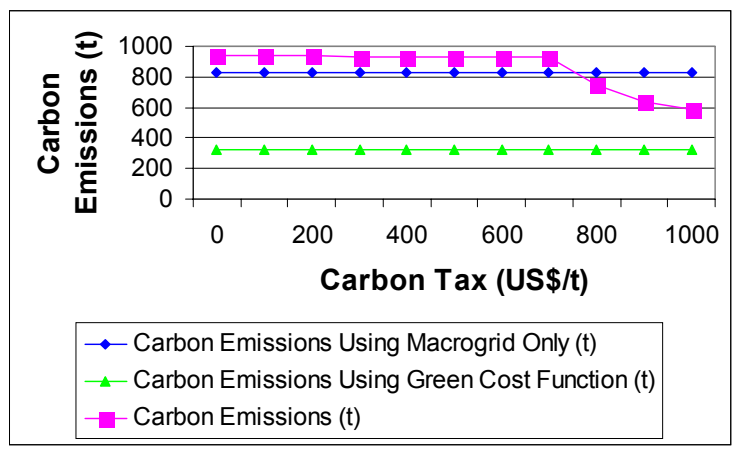

Figure 15. Carbon Emissions Comparison for the Base Case

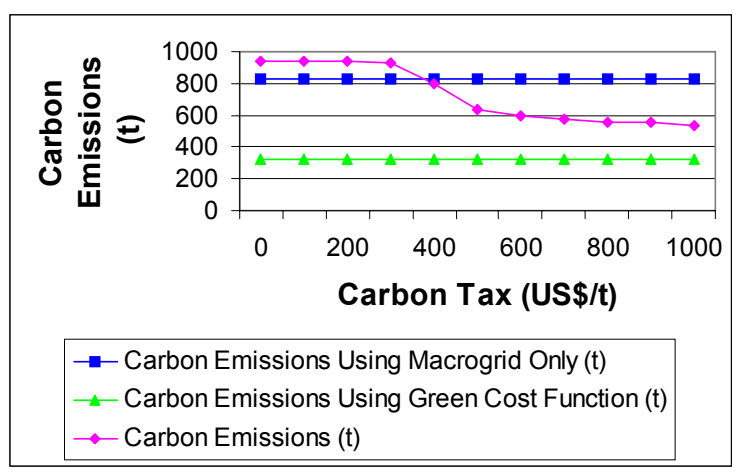

Figure 17. Carbon Emissions

Comparison for the $25 \%$ Subsidy Case

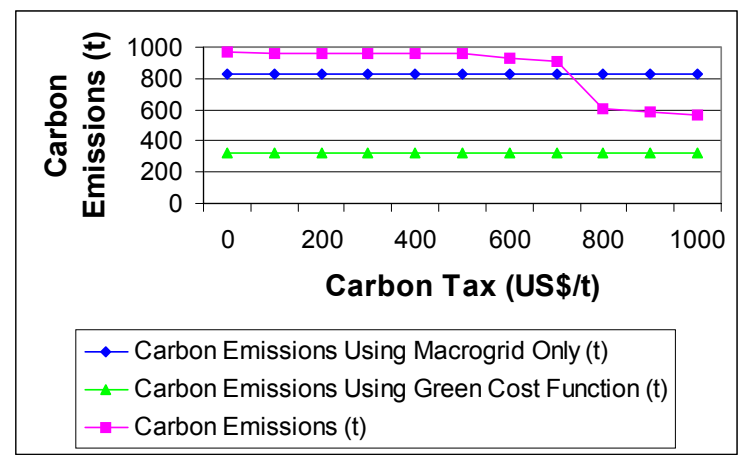

Figure 16. Carbon Emissions

Comparison for the Disco SDG\&E Tariff Case
Figure 18. Carbon Emissions

Comparison for the $50 \%$ Subsidy Case

\section{Conclusions}

In this paper, we construct an economic model to evaluate the effect of DER technology adoption by a hypothetical $\mu$ Grid on carbon emissions. The $\mu$ Grid contains California commercial customers. It has to meet its electricity load at minimum cost either by purchasing electricity from the macrogrid or by installing onsite generation resources. Its costs include carbon taxes in addition to the costs of purchasing electricity, installing DER technologies, and operating and maintaining DER technologies. By solving the resulting optimization problem in GAMS, we obtain the extent of DER technology adoption and resulting carbon emissions for a given regulatory environment and level of carbon taxation.

We find that while DER technology adoption increases with carbon taxation, the effect is not uniform, since non-renewable DER technology generates electricity with a higher carbon content than the electricity provided by the macrogrid. In most cases, the carbon tax must exceed US $\$ 400 / t$ before "green" DER technologies are adopted. Similarly, the impact of the carbon tax on carbon emissions abatement is marginal for carbon tax levels below US $\$ 400 / \mathrm{t}$. Indeed, some carbon emissions abatement does occur for low levels of carbon taxation, but this is a consequence of the $\mu$ Grid's purchasing more electricity from the macrogrid, which has a slightly lower carbon emissions rate than most of the DER technologies. Only when the turnkey costs of "green" technologies are reduced by $50 \%$, that significant (i.e., greater than $20 \%$ ) carbon emissions abatement is realized at carbon tax levels less than US $\$ 400 /$ t. Hence, according to our model, the most effective strategy for reducing carbon emissions is to provide a significant subsidy towards the turnkey costs of "green" technologies. The 
subsidies are also likely to accelerate a significant decline the costs of these technologies during the coming years. This will enable a greater reduction in carbon emissions at a lower level of carbon taxation.

In future work, the model will be enhanced by including hourly variations in the macrogrid carbon emissions rate, seasonal variation in the fuel prices, more "green" DER technologies, and CHP. In particular, with CHP, the $\mu$ Grid 's cost of satisfying both electricity and heat loads could be jointly optimized. CHP will give the $\mu$ Grid more opportunity to reduce its carbon emissions as well as improve the economics, thereby inducing more DER technology adoption.

\section{Bibliography}

Akbari, H., L. Rainer, K. Heinemeier, J., Huang, and E. Franconi. 1993. "Measured Commercial Load Shapes and Energy-Use Intensities and Validation of the LBL End-use Disaggregation Algorithm.” Berkeley, Lawrence Berkeley National Laboratory, pp. 224.

European Commission, E.C. 2001. "European Climate Change Programme Final Report," Directorate General of the Environment, European Union, Brussels, Belgium, June 2001.

Marnay, Chris, Raquel Blanco, Kristina S. Hamachi, Cornelia P. Kawaan, Julie G. Osborn, and F. Javier Rubio. "Integrated Assessment of Dispersed Energy Resources Deployment.” LBNL-46082, June 2000.

Marnay, Chris, Joseph S. Chard, Kristina S. Hamachi, Timothy Lipman, Mithra M. Moezzi, Boubékeur Ouaglal, and Afzal S. Siddiqui. "Modeling of Distributed Energy Resources Customer Adoption." LBNL Working Paper, August 2001.

Piagi, Paolo and Robert H. Lasseter. "Industrial Application of MicroGrids." Power System Engineering Research Center, University of Wisconsin-Madison, October 2001.

SCE, S. C. E. 1989. "End use metered data for commercial buildings." ADM for SCE, pp. 222.

van Sambeek, Emiel. "Distributed Generation in Competitive Electricity Markets". Center for Energy and Environmental Policy, Working Paper no. 00-S4, June 2000.

Weinberg, C.J., J.J. Iannucci, and M.M. Reading. "The Distributed Utility: Technology, Customer, and Public Policy Changes Shaping the Electrical Utility of Tomorrow," Energy Systems and Policy, vol. 15, pp. 307-322. 